\title{
Combination treatment with bevacizumab plus erlotinib for meningeal carcinomatosis of afatinib-resistant EGFR mutated lung cancer without T790M mutation: a case report
}

\author{
Shinji Chiba ${ }^{1}$, Masachika Akiyama ${ }^{1}$, Kazuhiro Yakuwa ${ }^{1}$, Hideomi Sato ${ }^{1}$, Kunio Hirano ${ }^{1}$, Yu Utsumi ${ }^{1}$, \\ Hiromi Nagashima ${ }^{1}$, Tamotsu Sugai ${ }^{2}$, Makoto Maemondo ${ }^{1}$ \\ ${ }^{1}$ Division of Pulmonary Medicine, Department of Internal Medicine, Iwate Medical University School of Medicine Yahaba, Iwate, Japan; \\ ${ }^{2}$ Department of Molecular Diagnostic Pathology, Iwate Medical University School of Medicine Yahaba, Iwate, Japan \\ Correspondence to: Makoto Maemondo, MD, PhD. Division of Pulmonary Medicine, Department of Internal Medicine, Iwate Medical University \\ School of Medicine, 2-1-1, Idaidori, Yahaba-cho, Shiwa-gun, Iwate, 028-3695, Japan. Email: maemondo-ma693@aioros.ocn.ne.jp.
}

\begin{abstract}
Meningeal carcinomatosis in lung cancer is known to have a very poor prognosis. Here we report a case in which bevacizumab plus erlotinib (BE) was effective against meningeal carcinomatosis from afatinib-resistant EGFR mutation-positive lung cancer. A 61-year-old man started afatinib, a $2^{\text {nd }}$ generation molecular targeting drug, as first-line treatment for lung adenocarcinoma cT1bN0M1a stage IVA harboring EGFR exon19 deletion mutation. This treatment shrank the tumor and allowed sustained control of tumor growth. After 19 months from the start of treatment, head MRI revealed brain metastasis in the cerebellum and meningeal carcinomatosis with loss of appetite and slurred speech, in response to which whole-brain irradiation was performed. Head MRI 1 month after whole-brain irradiation showed no change in the disseminated lesions of the cerebellum. In Japan, osimertinib treatment after failure of EGFR-TKI treatments requires the T790M mutation in the tumor, blood or body fluid, so BE treatment was started as second-line treatment. Brain MRI showed improvement in cerebellar disseminated lesions 1 month after the start of $\mathrm{BE}$ treatment. BE treatment controlled intrapulmonary metastases, pleural disseminated lesions and meningeal carcinomatosis for 6 months. BE treatment as second-line treatment should be considered as an option for meningeal carcinomatosis of EGFR tyrosine kinase inhibitor (TKI) -resistant EGFR mutated lung cancer.
\end{abstract}

Keywords: Non-small cell lung cancer (NSCLC); meningeal carcinomatosis; erlotinib; bevacizumab; case report

Submitted Jul 14, 2021. Accepted for publication Oct 26, 2021.

doi: 10.21037/apm-21-1885

View this article at: https://dx.doi.org/10.21037/apm-21-1885

\section{Introduction}

Approximately $10 \%$ of cases of EGFR mutant non-small cell lung cancers (NSCLCs) involve meningeal carcinomatosis, leading to a worse course $(1,2)$. The prognosis for meningeal carcinomatosis is 4 to 6 weeks without treatment and 2 to 3 months in treated cases $(3,4)$. After EGFR-TKIs provide significant benefit to patients with EGFR mutation-positive lung cancer, central nervous system recurrences often appear (5). Effective treatments for meningeal carcinomatosis have not been established other than treatment with osimertinib, which requires detection of the T790M mutation. Here, we report a case of EGFR mutation-positive lung cancer resistant to $2^{\text {nd }}$ generation EGFR-TKI in which $\mathrm{BE}$ treatment controlled meningeal carcinomatosis for a long period. We present the following case in accordance with the CARE reporting checklist (available at https://apm. amegroups.com/article/view/10.21037/apm-21-1885/rc).

\section{Case presentation}

A 61-year-old male was referred from another hospital to our hospital for diagnosis and treatment of a nodule in the 


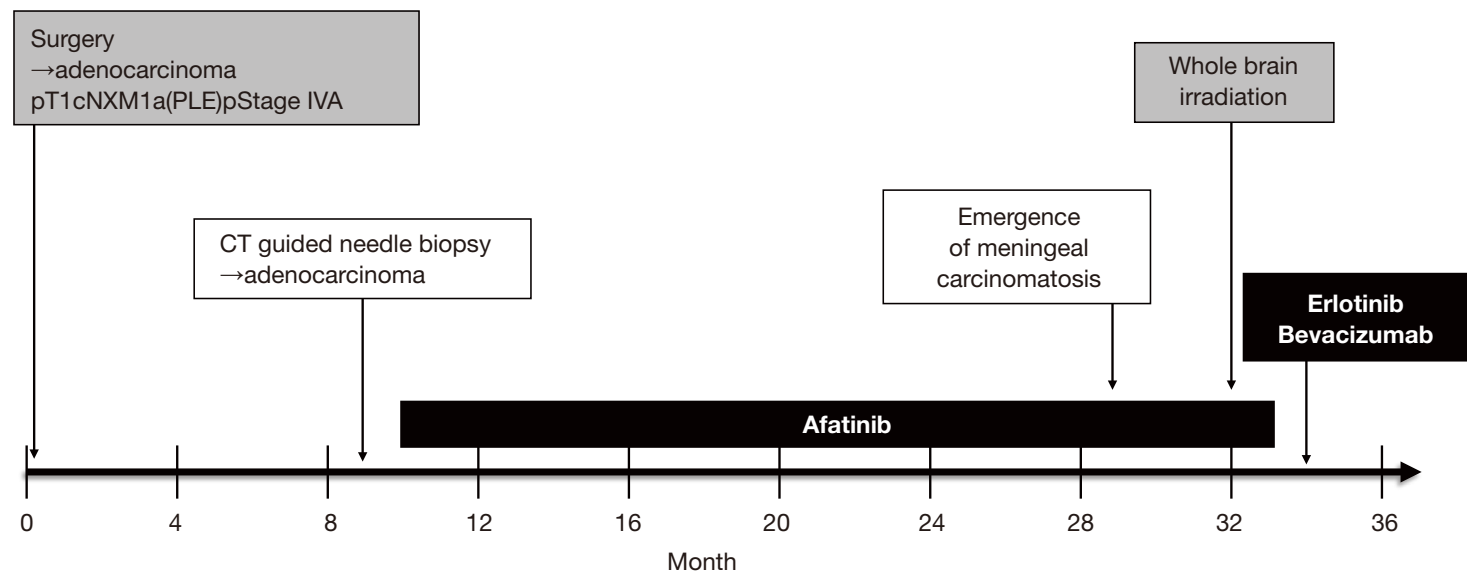

Figure 1 Timeline of treatments and examinations is shown. Black boxes and gray boxes indicate EGFR-TKI treatments and local treatments, respectively. PLE, pleural involvement; CT, computed tomography.
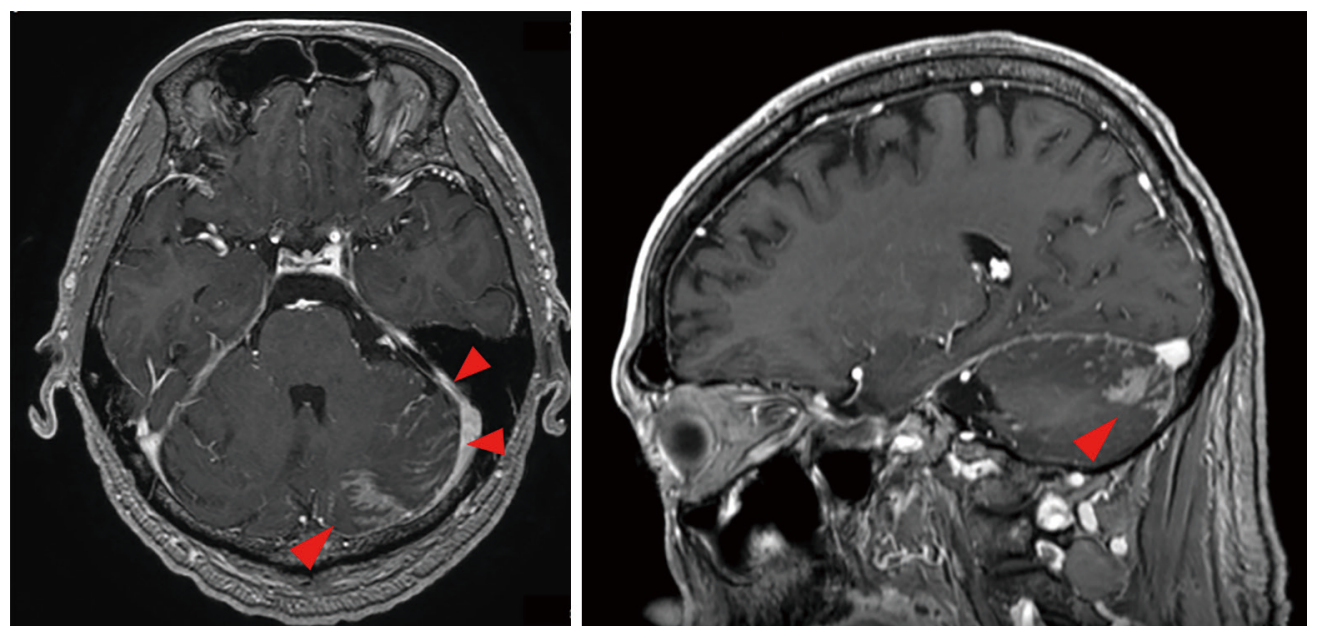

Figure 2 Contrast-enhanced MRI of the head with axis view (left panels) and sagittal view (right panels) showing disseminations seeded along the cerebellar sulcus. The red arrow heads indicate meningeal dissemination. MRI, magnetic resonance imaging.

lower right lobe of the lung. He had no overt symptoms associated with the chest lesion. He had a smoking history of 7.5 pack-years and no other notable medical history. Chest CT showed disseminated lesions in the pleura besides the primary lung lesion. Surgical partial resection of the lower right lobe and biopsy of the nodules on the parietal pleura were performed to confirm the dissemination. The histological examination provided a diagnosis of stage IV adenocarcinoma harboring an activating EGFR exon 19 deletion mutation. The patient was followed up without active treatment in accordance with his wishes. Six months after resection, a nodular shadow in the right middle lobe was detected. This lesion was diagnosed by CT-guided lung biopsy as a recurrence of lung adenocarcinoma.

Treatment with afatinib (40 mg/day) was started. The nodular shadow in the right middle lobe shrunk to the extent of a partial response. Extensive skin eruption occurred 20 days after the start of administration and the dose of afatinib was reduced to $30 \mathrm{mg} /$ day. Nineteen months after the start of the afatinib treatment, head MRI revealed brain metastasis and meningeal carcinomatosis in the cerebellum. Whole-brain irradiation was performed under continuing afatinib treatment (timeline so far: Figure 1). Head MRI 1 month after whole-brain irradiation showed no remarkable change in the disseminated lesions of the cerebellum (Figure 2). He exhibited gradual loss of appetite and 
development of slurred speech, and developed signs of meningeal irritation. A plasma EGFR test was negative for both exon 19 deletion mutation and T790M mutation.

Treatment with bevacizumab $(15 \mathrm{mg} / \mathrm{kg}$ every 3 weeks) plus erlotinib (150 mg/day) (BE) was started in place of afatinib treatment. Cerebrospinal fluid (CSF) puncture was performed 5 days after the start of treatment. The CSF examination revealed atypical cells in liquor (Figure 3). Bacterial and viral meningitis were considered as differential diagnoses, and were ruled out by a cerebrospinal fluid test. EGFR mutation test of CSF was positive for exon 19 deletion mutation but negative for T790M mutation. We diagnosed this situation as meningitis

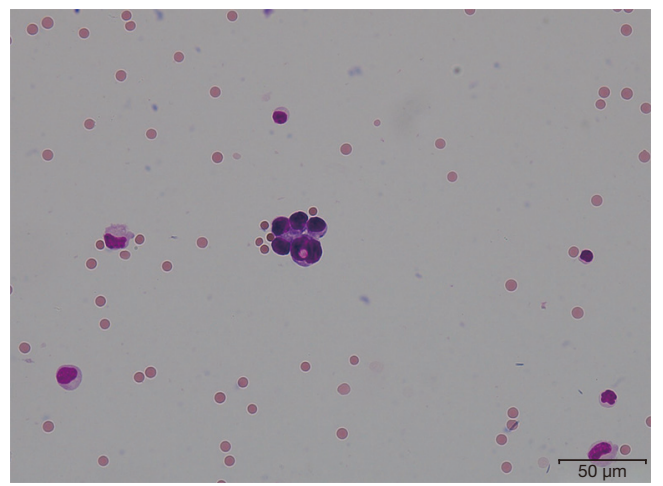

Figure 3 Pictures of CSF cytology using Giemsa stain. A few atypical cells were found. CSF, cerebrospinal fluid. carcinomatosis which has an extremely poor prognosis. Two weeks After the start of BE treatment, he showed elevation of total bilirubin (grade 2) and erlotinib was withdrawn for 2 weeks. One month after the start of treatment, head MRI showed shrinkage of the nodule in the left cerebellar hemisphere and diminished dissemination along the sulcus of the cerebellum (Figure 4). The loss of appetite and slurred speech were improved. After improvement of bilirubin, erlotinib was restarted at $100 \mathrm{mg}$ every other day. We considered that malignant meningitis had responded well to BE treatment and this treatment was continued. A total of 10 cycles of bevacizumab in addition to daily erlotinib treatment was administered. The patient had survived with good performance status for 6 months from the start of BE treatment. Subsequently, slurred speech recurred and head MRI revealed FLAIR signals on the surface of the cerebellum, bilateral cistern ambiens, and the surface of the cerebellar tentorium. It was confirmed that meningeal carcinomatosis had progressed. After failure of BE treatment, a plasma EGFR mutation test was positive for exon 19 deletion mutation and negative for T790M mutation.

All procedures performed in the study were in accordance with the ethical standards of the institutional and/or national research committee(s) and with the Helsinki Declaration (as revised in 2013). Written informed consent was obtained from the patient for publication of this case report and accompanying images. A copy of the written
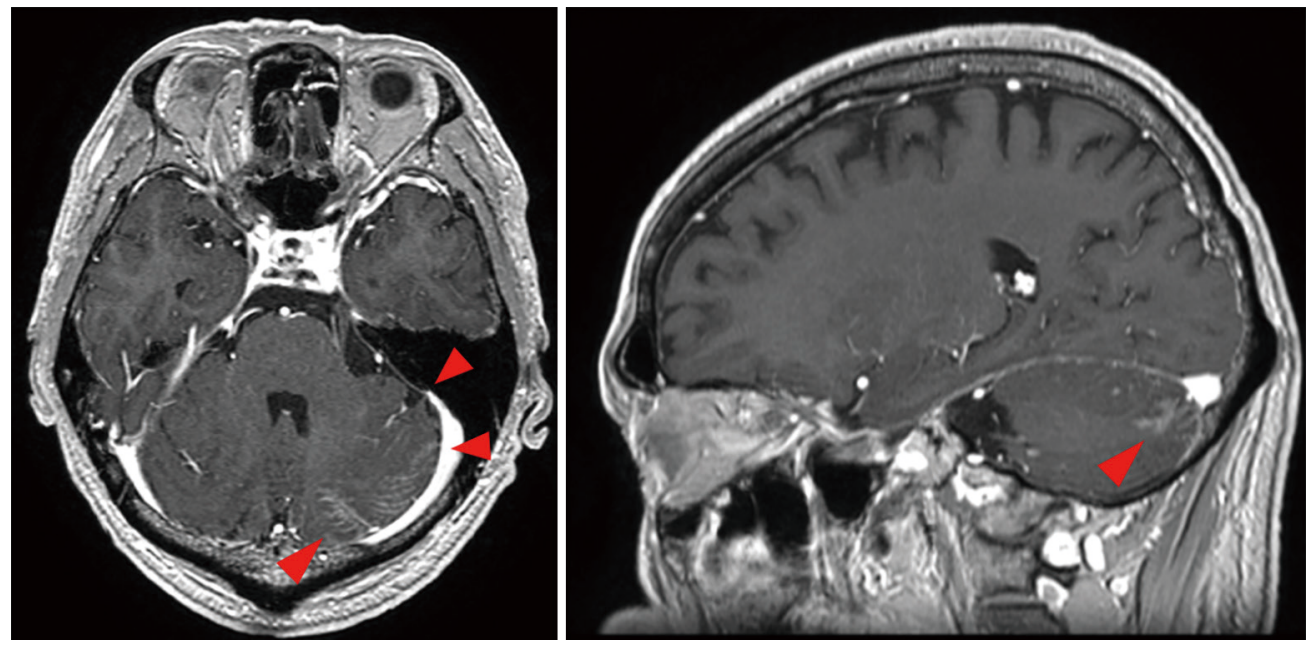

Figure 4 Contrast-enhanced MRI of the head with axis view (left panels) and sagittal view (right panels) showing reduced dissemination along the cerebellar sulcus 1 month after BE treatment. The red arrow heads indicate meningeal dissemination. BE, bevacizumab plus erlotinib. 
consent is available for review by the editorial office of this journal.

\section{Discussion}

In this case, BE treatment was administered as the secondline treatment for EGFR mutation-positive lung cancer, and meningeal carcinomatosis was controlled for long periods.

Meningeal carcinomatosis is a disease in which cancer cells spread from tumors to the meninges hematogenously or lymphatically and proliferate there (6). Meningitis carcinomatosis is characteristics by the spread of tumor cells into both the cerebrospinal fluid (CSF) and the arachnoid membrane, and infiltration into the subarachnoid space (7). Central nervous system metastases have often been considered as a "sanctuary" of disease progression because the blood-brain barrier (BBB) prevents the delivery of antineoplastic agents in the meninges.

The incidence of meningeal carcinomatosis of EGFR mutation-positive NSCLC is $9.4 \%$, which is higher than the $1.7 \%$ incidence of EGFR mutation-negative NSCLC. Although the mechanism by which meningeal carcinomatosis occurs more frequently in EGFR mutant patients is thought to be multifactorial, it is believed to be mainly due to prolonged survival and inadequate penetration of EGFR-TKIs into the CSF (1).

Erlotinib is known to have good CSF penetration rates. In a study comparing concentrations in CSF between erlotinib and gefitinib in 15 patients with EGFR mutated NSCLC, the CSF concentrations of erlotinib were $28.7 \pm 16.8 \mathrm{ng} / \mathrm{mL}(66.9 \pm 39.0 \mathrm{nM})$ and the penetration rate was $2.77 \% \pm 0.45 \%(8)$. On the other hand, in another study evaluating 11 patients with EGFR mutationpositive NSCLC receiving afatinib, the levels of afatinib in blood and CSF (mean \pm SD) were 233.26 \pm 195.40 and $3.16 \pm 1.95 \mathrm{nM}$, respectively. The CSF penetration rate was $2.45 \% \pm 2.91 \%$ (9). Erlotinib and afatinib penetration rates were the same. Although osimertinib was expected to have better efficacy in treatment of CNS lesions due to higher penetration rates, osimertinib has not been approved in Japan for patients without detection of T790M mutation after failure of EGFR-TKI.

Bevacizumab is a monoclonal antibody that works against vascular endothelial growth factor (VEGF). Antitumor efficacies of bevacizumab are derived from three main factors. First, suppressing angiogenesis in tumor tissue inhibits tumor growth through the supply of oxygen and nutrients to the tumor. Second, normalization of vascular structures reduces vascular permeability, and enhances transfer of anti-tumor agents into tumor tissue. Tumor vasculature is composed of immature vessels and leads to high interstitial pressure in the tumor, which inhibits transfer of the agents from intravascular space to the interstitial space of the tumor. Bevacizumab improves drug delivery through reducing interstitial pressure by vascular normalization (10). Third, bevacizumab has a positive effect on the immune environment, for example by inhibiting regulatory $\mathrm{T}$ cells and myeloid-derived suppressor cells (MDSCs) (11). These three factors might each work to some extent in EB treatment. We conducted a phase III NEJ026 study comparing $\mathrm{BE}$ treatment with erlotinib (E) treatment for Japanese patients with EGFR mutation-positive NSCLC, in which the primary endpoint was progression free survival (PFS). BE treatment significantly prolonged PFS compared to erlotinib alone (16.9 vs. 13.3 months, respectively; $\mathrm{HR}=0.605 ; 95 \% \mathrm{CI}: 0.417-0.877 ; \mathrm{P}=0.01573)$ (12). Some other reports showed BE treatment if effective on central nervous system metastasis of EGFR mutationpositive NSCLC $(13,14)$.

In the treatment of CNS metastases, bevacizumab may increase the CSF concentration of EGFR-TKIs, and the combination of erlotinib and bevacizumab has been suggested to have a higher CSF penetration rate than erlotinib alone (15). We speculate that the use of bevacizumab in addition to erlotinib was a factor in the observed efficacy in afatinib-refractory carcinomatous meningitis.

There is insufficient evidence to suggest which EGFRTKIs, or which combinations, are the most effective for meningeal carcinomatosis of EGFR-positive NSCLC. Although osimertinib is considered to have a high concentration rate of permeability into the central nervous system (16), use of osimertinib for T790M negative patients after other EGFR-TKI treatments is not permitted. In this situation, with no indication for osimertinib, $\mathrm{BE}$ treatment can be effective for meningeal carcinomatosis in T790Mnegative cases after $1^{\text {st }}$ or $2^{\text {nd }}$ generation EGFR-TKI treatment. Although the effectiveness of BE treatment for brain metastasis was not confirmed in the NEJ026 study (17), patients with advanced brain metastases often have peritumoral edema in the brain and neurological symptoms, and such patients were excluded from the NEJ026 study. The current case report suggests that BE treatment may have clinical effects on advanced and symptomatic CNS metastasis.

BE treatment was considered to be an effective 
treatment option in patients suffering from severe EGFRTKI-resistant meningeal carcinomatosis. Further case accumulation and research are warranted.

\section{Acknowledgments}

The authors thank the participating patients and their families. We are grateful to Dr. Nishiya, pathologist, for providing pathology images and to James Hobbs, English professor for correcting our English.

Funding: None.

\section{Footnote}

Reporting Checklist: The authors have completed the CARE reporting checklist. Available at https://apm.amegroups. com/article/view/10.21037/apm-21-1885/rc

Peer Review File: Available at https://apm.amegroups.com/ article/view/10.21037/apm-21-1885/prf

Conflicts of Interest: All authors have completed the ICMJE uniform disclosure form (available at https://apm.amegroups. com/article/view/10.21037/apm-21-1885/coif). MM received lecture fees from Chugai pharm. The other authors have no conflicts of interest to declare.

Ethical Statement: The authors are accountable for all aspects of the work in ensuring that questions related to the accuracy or integrity of any part of the work are appropriately investigated and resolved. All procedures performed in the study were in accordance with the ethical standards of the institutional and/or national research committee(s) and with the Helsinki Declaration (as revised in 2013). Written informed consent was obtained from the patient for publication of this case report and accompanying images. A copy of the written consent is available for review by the editorial office of this journal.

Open Access Statement: This is an Open Access article distributed in accordance with the Creative Commons Attribution-NonCommercial-NoDerivs 4.0 International License (CC BY-NC-ND 4.0), which permits the noncommercial replication and distribution of the article with the strict proviso that no changes or edits are made and the original work is properly cited (including links to both the formal publication through the relevant DOI and the license). See: https://creativecommons.org/licenses/by-nc-nd/4.0/.

\section{References}

1. Li YS, Jiang BY, Yang JJ, et al. Leptomeningeal Metastases in Patients with NSCLC with EGFR Mutations. J Thorac Oncol 2016;11:1962-9.

2. Kuiper JL, Hendriks LE, van der Wekken AJ, et al. Treatment and survival of patients with EGFRmutated non-small cell lung cancer and leptomeningeal metastasis: A retrospective cohort analysis. Lung Cancer 2015;89:255-61.

3. Grossman SA, Krabak MJ. Leptomeningeal carcinomatosis. Cancer Treat Rev 1999;25:103-19.

4. Wasserstrom WR, Glass JP, Posner JB. Diagnosis and treatment of leptomeningeal metastases from solid tumors: experience with 90 patients. Cancer 1982;49:759-72.

5. Lee YJ, Choi HJ, Kim SK, et al. Frequent central nervous system failure after clinical benefit with epidermal growth factor receptor tyrosine kinase inhibitors in Korean patients with nonsmall-cell lung cancer. Cancer 2010;116:1336-43.

6. Patil S, Rathnum KK. Management of leptomeningeal metastases in non-small cell lung cancer. Indian J Cancer 2019;56:S1-9.

7. Mack F, Baumert BG, Schäfer N, et al. Therapy of leptomeningeal metastasis in solid tumors. Cancer Treat Rev 2016;43:83-91.

8. Togashi Y, Masago K, Masuda S, et al. Cerebrospinal fluid concentration of gefitinib and erlotinib in patients with non-small cell lung cancer. Cancer Chemother Pharmacol 2012;70:399-405.

9. Tamiya A, Tamiya M, Nishihara T, et al. Cerebrospinal Fluid Penetration Rate and Efficacy of Afatinib in Patients with EGFR Mutation-positive Non-small Cell Lung Cancer with Leptomeningeal Carcinomatosis: A Multicenter Prospective Study. Anticancer Res 2017;37:4177-82.

10. McCrudden KW, Hopkins B, Frischer J, et al. Anti-VEGF antibody in experimental hepatoblastoma: suppression of tumor growth and altered angiogenesis. J Pediatr Surg 2003;38:308-14; discussion 308-14.

11. Koinis F, Vetsika EK, Aggouraki D, et al. Effect of FirstLine Treatment on Myeloid-Derived Suppressor Cells' Subpopulations in the Peripheral Blood of Patients with Non-Small Cell Lung Cancer. J Thorac Oncol 2016;11:1263-72.

12. Saito H, Fukuhara T, Furuya N, et al. Erlotinib plus bevacizumab versus erlotinib alone in patients with EGFR-positive advanced non-squamous non-small-cell 
lung cancer (NEJ026): interim analysis of an open-label, randomised, multicentre, phase 3 trial. Lancet Oncol 2019;20:625-35.

13. Chikaishi Y, Kanayama M, Taira A, et al. Effect of erlotinib plus bevacizumab on brain metastases in patients with non-small cell lung cancer. Ann Transl Med 2018;6:401.

14. Jiang T, Zhang Y, Li X, et al. EGFR-TKIs plus bevacizumab demonstrated survival benefit than EGFRTKIs alone in patients with EGFR-mutant NSCLC and multiple brain metastases. Eur J Cancer 2019;121:98-108.

15. Sakata Y, Kawamura K, Shingu N, et al. Erlotinib plus bevacizumab as an effective treatment for leptomeningeal

Cite this article as: Chiba S, Akiyama M, Yakuwa K, Sato H, Hirano K, Utsumi Y, Nagashima H, Sugai T, Maemondo M. Combination treatment with bevacizumab plus erlotinib for meningeal carcinomatosis of afatinib-resistant EGFR mutated lung cancer without T790M mutation: a case report. Ann Palliat Med 2022;11(8):2745-2750. doi: 10.21037/apm-21-1885 metastases from EGFR mutation-positive non-small cell lung cancer. Lung Cancer 2016;99:120-2.

16. Yang JCH, Kim SW, Kim DW, et al. Osimertinib in Patients With Epidermal Growth Factor Receptor Mutation-Positive Non-Small-Cell Lung Cancer and Leptomeningeal Metastases: The BLOOM Study. J Clin Oncol 2020;38:538-47.

17. Maemondo M, Saito H, Furuya N, et al. NEJ026: Final overall survival analysis of bevacizumab plus erlotinib treatment for NSCLC patients harboring activating EGFR-mutations. J Clin Oncol 2020;38:9506. 